\title{
Designing social media into university learning: technology of collaboration or collaboration for technology?
}

\author{
Elaine Tay and Matthew Allen \\ Department of Internet Studies, Curtin University, Perth, Australia
}

Email address: e.tay@curtin.edu.au and m.allen@curtin.edu.au

\begin{abstract}
Using the example of an undergraduate unit of study that is taught both on-campus and externally, but uses Internet-based learning in both cases, we explore how social media might be used effectively in higher education. We place into question the assumption that such technologies necessarily engage students in constructivist learning; we argue that the affordances of social media must be complemented by social affordances, designed into the learning experience, which thereby generate the necessary connection between students' motivations to study and their motivations to exploit social media. We demonstrate, via the example given, how assessment structures and strategies are the most effective focus when attempting to create the pedagogical affordances that might lead to collaborative learning.
\end{abstract}

Keywords: social media, online learning, authentic assessment

\section{Introduction}

This article reports on the specific processes used to redesign a single unit of study within the Internet Communications major offered by the Department of Internet Studies at Curtin University as an example of the way in which innovative uses of so-called Web 2.0 technologies for higher education can be approached. The unit under discussion is Internet Commerce and Consumers 205 (hereafter NET205), a second-year unit that, as described in its syllabus statement, allows students to study the dynamics of Internet commerce, including the 'free' services that are part of the attention economy"; students "analyse the importance for the Internet of an alternative economic form - the gift economy...[and] will understand how the Internet might, within capitalism, be associated with economic rewards and risks and how developments on the Internet have altered business practices and approaches.” NET205 is studied by a mix of off- and on-campus students, enrolled both through Curtin University directly and through Open Universities Australia. Students are either enrolled in the BA (Internet Communications) or the BA (Mass Communication). Thus, the unit has a diverse cohort of students from several courses with different motives, attachments and expectations; students also enter with a wide range of preparations and abilities.

Given the subject matter of the unit and the fact that most students complete it without attending campus, the use of online learning is essential for the achievement of student learning outcomes. The question that faced staff involved in this unit when it was redesigned in 2009 was what might be the most effective use of online learning, and with what particular unit design, so as to best exploit the affordances of social media.

The first section of the paper provides the broad context within which this unit of study was redeveloped; while undertaken within a university-wide program of reform, the redevelopment was informed principally a desire to design effective formative assessment structures as the heart of the learning process; it also involved close engagement with social media and with the educational principles of constructivism. The second section of the paper 
explores the origins of this engagement more closely, emphasizing in particular the relationship between new technologies and newly promoted theories of the social construction of knowledge. The remainder of the paper presents our description and analysis of the planned and actual outcomes of the redesigned social-media enabled NET205 unit of study in 2009.

\section{Curriculum reform within Internet Studies}

In 2009 and 2010, Internet Studies redesigned its units of study and undergraduate major in Internet Communications as part of the university's overall curriculum reform program, Curriculum 2010 (C2010). While Internet Studies has been an innovative user of online learning approaches since the turn of the century (see for example Allen, 2001), C2010 provided the department with the opportunity to reshape its approach to teaching and learning. The department determined that, building on its existing expertise in the use of the Internet for education, and reflecting the particular subject matter which it was teaching, its curriculum would be reformed with a particular emphasis on innovative assessment. This focus would improve student engagement with their learning because assessment plays such an important role in motivating and structuring students' attention to their studies (Allen, 2009a; also Volet and Järvelä, 2001). Assessment was therefore the main aspect of the redesign process, rather than curriculum, and used as the foundation on which all other decisions were made. Assessment approaches were designed also to draw specifically upon the emerging state of knowledge work in a world marked by widespread information and communication networking, what Allen \& Long (2009) describe as the knowledge networking paradigm.

Central to achieving these results was a close engagement with social media and related Web 2.0 online services and approaches (Anderson, 2007; see also Bruns, 2007), employing a nuanced and progressive use of social media to support learning activities and their assessment. This approach recognised that social media affordances are not simply 'built in' to the technologies; the very nature of affordances is such that they must be taken up and activated (Norman, 1988). The technologies do not of themselves result in significant differences in human behaviour, even though there are an essential part of such change. Therefore, staff in the department determined that simply incorporating social media services and technologies into units of study would not of itself lead to any meaningful improvement in the learning outcomes for students. This view was sustained even given the apparent turn by society and students to 'social media' in their everyday lives, as often reported by some of the more enthusiastic advocates of Web 2.0 applications for education (e.g. Crook 2008; Diaz, 2010; Ebner, Holzinger \& Maurer, H, 2007). While it is clear that a different environment has now emerged for students because of the widespread use of applications such as Facebook, YouTube and so on, this change alone by no means guarantees that learners would immediately be able to adopt and benefit from social media affordances if they were included in their studies (see for example Dron, 2007). In sum, staff saw both the necessity of including greater use of social media in teaching and, at the same time, believed that neither social media technologies themselves, nor the informal and personal cultures of use that students had developed, would necessarily mean that this innovation would - without close attention to pedagogic design - reliably improve students’ outcomes.

The approach to curriculum reform, especially as it related to the uses of novel technologies in learning, was also informed by the broad principles of social constructivism (Bednarz, Garrison, \& Larochelle, 1998; Blais, 1988; Von Glasersfeld, 1995). Since the department's inception, all of its units had been designed to maximize student-centred 
learning and build collaborative partnerships between educators and learners. Such partnerships gave real effect to the idea that students learn best when they are required to engage actively with the curriculum material in ways that emphasis the individual construction of meaning and knowledge in a social setting involving interchanges between learners about the nature and content of their studies. Because Internet Studies has been using online learning technologies and techniques since 1999, the department has considerable expertise in exploring how web-based and other internet-enabled approaches can actually provide a greater degree of social constructivist engagement than more traditional settings (a useful selection of early ideas can be found in Wolfe, 2001). Yet the department was also aware of the resurgence of interest in constructivism within educators, based on the rise of social media and Web 2.0 (McLoughlin and Lee, 2007). Thus, while not ascribing any unique ability to these more recent forms of online learning to imbue education with a necessarily constructivist approach, tyhe dpeartment nevertheless started from the assumption that social media - because of its avowedly participatory, co-creative nature - would play a major role in reinforcing and extending the use of constructivism within its curriculum.

Learners can, it seems, experience social media as collaborative and thus are more likely to become engaged in a constructivist process. In part social media affords students collaborative potential because of the particular ways in which the technology works; yet also important are the actions of teachers who establish this 'new' form of learning and assessment in contrast to old approaches. Even the fact students themselves may already understand these technologies as 'collaborative' relative to other uses of the Internet may play a part. And, from collaboration, comes the possibility of constructivism: what then has been the new wave of enthusiasm for constructivism associated with the rise of social media and Web 2.0?

\section{The rise of social media: opportunities for constructivism}

Over the past five or so years, higher education research and development has seen a resurgence of explicit attention to constructivism that coincides with, but is not wholly attributed to, the rising importance in broader society of Web 2.0 and social media (Collis \& Moonen, 2008; Payne, 2009). These new formations of Internet technology and usage involve changes in: the perceived affordances of Internet-based communications and information sharing (Musser, 2006; O'Reilly, 2005), particularly with reference to usergenerated content or "produsage" (Bruns, 2009); the cultures of media use in a convergent or remixed media environment (Fagersjord, 2010; Jenkins, 2009); and the refinement of our understandings of a knowledge society (Poster, 1990). Manovich, for example, describes the shift "from media to social media" as the result of spurred technologies and practices that allow ordinary Internet users, rather than media professionals, to engage actively in organising, discussing, remixing and creating content (2009, p. 320). All around us software such as blogs, wikis, social bookmarking and tagging, web-feeds (RSS), podcasting and media sharing, readily available hardware for text, audio and visual production and publication, and sites such as Facebook, YouTube, Twitter, Delicious, FriendFeed, provide the mechanism to give effect to this shift.

While there is still debate about the best way to label these changes - and Web 2.0 remains popular - the term social media is preferable. Web 2.0, as Allen (2009b) has argued, more properly describes a particular moment in the history of web development, both social

and technical. The term, social media, by contrast, situates technological development online in the cultural and social practices of users, rather than a technology-oriented paradigm of better versions. For educators, thinking in terms of social media emphasises the interplay 
between the social and technological that produces the affordances with which we are most concerned.

Yet precise ideas of what constitutes social media are still elusive, although the identification of common tropes has recently become easier as more and more writers pay greater attention to the social affordances of Internet technologies as a whole as well as to the individual applications. Within higher education discourse, Lee \& McLoughlin provide an excellent summary of the general affordances of social media; they describe how it facilitates the co-creation of content and value-adding by users, allowing the rise of "prosumers," that is, the potential and realisation of participants as both consumers and producers of content (2008, p. 2). The architecture of openness within social media adds value by exploiting the participation of multitudes of people, not just individuals and their direct contacts, better mobilizing the often-promised benefits of network effects via the Internet of and as Surowiecki put it "wisdom of crowds" (cited in Lee \& McLoughlin, 2008, p. 2). Other writers point to the way knowledge work changes because of "interconnections, content creation and remixing, and interactivity” (Greenhow, Robelia, \& Hughes, 2009, p. 249).

Eijkman (2009) describes how social software, as he terms it, enables an epistemology that decentralises authority over what counts as knowledge and the way knowledge is constructed, organised and distributed. Thus, such technologies promise to move education away from a knowledge-object orientation towards process-driven approaches - not what to know, but how to know. The epistemic shift that Eijkman describes was also identified by Barnett (2004), writing of a change in emphasis in higher education from knowing to being. Drawing on Sfard's metaphors to discuss notions of quality, Collis \& Moonen (2008) discuss the dissonance between the common presumption in teaching and learning of knowledge acquisition and the participatory approach of social media. In the latter situation, knowledge is social and learning is performative, and students best learn in communities of knowledge by gaining, Sfard's words, "the ability to communicate in the language of this community and act according to its norms ... The permanence of having (as emphasized by the acquisition approach) gives way to the constant flux of doing" (cited in Collis \& Moonen, 2008, p. 97). Of course, the possibility that social media might enable, or encourage, or demand a process and performance approach to learning does not mean that students - even when well-equipped with the tools and technologies of social media - readily accept this approach. Collis \& Moonen (p.96) point out students, not just instructors, tend to be familiar with and expect the traditional approach based around the transmission of content, rather than close engagement with learning processes, a point particularly relevant to our assessment design.

Nevertheless, there is the growing possibility of a mismatch between higher education practices which still rely on transmission and knowledge-centred approaches and the practices which students have intuitively developed in their everyday learning activities influenced by the epistemological foundations of social media. Greenhow, et al. bring together various sources to describe current students as "frequently creative, interactive, and media oriented; use Web 2.0 technologies in their everyday lives; and believe that more use of such technologies in school would lead to increased preparation and engagement" (2009, p. 247). One example is the way students prefer multiple methods of online communication, for instance, social networking, instant messaging, phone texting, to the traditional email and face to face communication used by instructors (Pew Internet Life Project research cited in Greenhow, et al., 2009). Preferences like these appear to stem from the participatory, collaborative and networked knowledge environment and suggest that students should be 
encouraged, through course design, instruction and assessment, to be adept at the skills of this environment.

The way in which educational writers discuss the value of social media - focusing on collaboration, sharing, participation, and so on - is clearly informed by a belief in the value of a social constructivist approach to learning. That is, the benefits of social media for learning emerge because these technologies promote a way of learning in which students construct their knowledge as a consequence of engaging with, discussing, and re-expressing the material to be learned, rather than just acquiring and repeating that content, and more importantly do so in a combined, or collected manner - one individual cannot learn as well as many working together. Social media is, among its proponents, imagined as variously: enabling social constructivist learning to occur (because of its affordances for collaborative rather than individual knowledge work); as requiring social constructivist learning (because students are somehow more naturally attuned now to that approach); or as enforcing social constructivism (because the technology will not permit any other kind of approach). The variety of responses by educational writers and theorists to social media therefore also demonstrates a range of views about the degree to which technology does or does not determine the outcomes of its adoption (Williams \& Edge, 1996). For some, social media (both as technology and cultural practice) might well force university academics to teach in ways that are different to the presumed norm of traditional content transmission; for others, the social engagement by universities and their students with these technologies will shape social media such that it promotes constructivism while not necessarily assuming this will always occur, or occur in the same way for any given group of teachers and learners.

We take the view that there is nothing inherent within the technologies of social media which determine that constructivism will be the necessary result of its application within education. Educators have recognised the problems posed by social media for assessment design and implementation: Gray, Thompson, Sheard, Clerehan \& Hamilton (2010), in their study of how higher education instructors have used social media in their assessment, point out that assessment design and implementation addressing student use of social media is still in its infancy. It is noticeable that many writers on learning and Web 2.0 ignore the fact that, at least a decade ago, the arrival of what we might now term Web 1.0 in society was greeted with similar claims that, inevitably or necessarily, learning would become constructivist as a result. Indeed, the very early work of Internet-based learning pioneers (for example Turoff, 1991, Hiltz, 1998 and Harasim, 1995) was similarly informed by constructivism ideals and expectations and yet, some 20 years later, despite the general availability and systemic application of networked computing in education, there is no evidence that this innovation has, of itself, led to increases in constructivist learning. Rather, we would argue, it is the particular pedagogic application of social media - not the technology itself - that will lead to a constructivist learning outcome. While social media might afford us possibilities for collaboration, shared content creation, and participation in knowledge building, those possibilities need to be actualized through the effective integration of social media into learning environments. Additionally, since assessment is an important driver of student learning, this integration needs to begin with the design of student assessment in a way that recognises the key affordances of the social media tools used. We will now explore how we attempted to achieve that integration in the unit NET205 and then report on the results from the first instance of teaching the unit. ${ }^{1}$ 


\section{Design for effective social media in learning}

\section{Assessment: the key design focus}

The learning outcomes for NET205 clearly define the kind of content that might be expected for a unit called Internet Commerce and Consumers, taught within a media and communications program. At the end of this unit, students are expected to be able to:

1) demonstrate understanding of the principles and practices which sustain Internet commerce;

2) analyse specific commercial events and occurrences to explain the nature of Internet economics;

3) demonstrate understanding of the way in which capitalism pervades the social and technological workings of the Internet in global society; and

4) assess critically the culture and practices of 'free' online labour, goods and services associated with Internet

Yet, for all the importance of the content, the starting point for the design decisions made in NET205 was not the 'knowledge' to be learned, but how best students might come to develop their own knowledge, within the broad frame of reference that these outcomes provide. A major aspect of all study at university is to produce graduates with broader skills and abilities. Thus, in NET205, students were also expected to become better knowledge workers via improving their ability to learn independently, work in teams with other students, reflect and review their own progress (self-assessment), and - given the nature of the degree program - utilise effectively the online tools and techniques relevant to these skills.

Based on the work of Gibbs (2006) and others (Biggs, 2003; Gibbs, Simpson, \& Macdonald, 2003; Joughin, 2009; Morgan \& Beaty, 1997) on assessment in higher education, the first priority was to design the assignments that students would complete. The structure of assessment in education both motivates and directs most student learning behaviour: not only does assessment demonstrate the value which teachers attach to some activities over others, but it also provides the focus on achievement which, either for personal satisfaction or external reward through grades, tends to be a major element in students' experience of their own learning at university. Kirkwood (2008) has suggested that assessment design also needs to fully exploit the affordances of ICT technologies and the desire to embed social media in the unit of study also justified the focus on assessment, since it is through assignments that students most effectively produce knowledge outcomes, rather than simply consuming them from reading or attending lectures. The assessment-oriented design was also heavily influenced by the established knowledge that authentic assignments generate greater learning outcomes in most cases by better motivating students because of the explicit link with a 'real-world' problem, outcome or situation. (Gulikers, Bastiaens, \& Kirschner, 2004; Herrington, Reeves, \& Oliver, 2006). The assessment structure then drove many other decisions about the design of the unit, including the technologies to be used, the way they were 'encoded' with learning expectations, the timing of activities, and the arrangement of both the content and the instructional scaffolding. ${ }^{2}$ 
The assessment structure consisted of a primary assignment, done by small teams of students and worth $50 \%$ of the available marks and due approximately 8 weeks into the 14week semester. This assignment required production of a substantial team-written report published online. This primary assignment was supported by two smaller, individual assignments. The first (worth 20\%), due within a month, had students review, in written form, technologies that might be useful for online collaboration, so as to prepare the ground for their potential use of those tools in their primary assignment. Then, at the end of the unit, students would present a traditional essay (30\%) which drew upon the work conducted in their teams, but which expressed their own individual analysis of Internet commerce and economics. While drawing on the material they would have used in the primary assignment, it enabled each student to achieve a personal outcome consonant with their ability and knowledge. In sum, the structure was designed to give students a holistic experience of assessment: each assignment materially contributed to others, or drew upon what had already been done; the structure also provided students with the opportunity to learn both individually and collectively and explore the differences between those two approaches.

As well as assignments, students were provided with substantial other material resources, readings, questions, activities and so on - as well as the usual instructions about when and what to do (with some important exceptions discussed below). However, we did not array and organise this material in a weekly fashion, simply to reflect the weeks of the semester. Rather, the unit's temporal sequence was arranged around the due dates for these assignments, with material presented as relevant to, or following on from, one or other assessment task. All materials were thereby linked to, and reinforced, the assessment structure and, in turn, made sense because they were there to aid students in achieving good results in assignments. Essentially, we designed a unit as 'one big assignment' and then created components for that assignment suitable for each part and purpose of the unit as a sequential experience. Let us now explore two of these assignments in more detail, and in doing so demonstrate how social media was involved, with particular reference to the way that our instructions to students about their completion of the task created the environment in which social media become effective for constructivist learning. ${ }^{3}$

\section{Assignment One: review of social software for collaboration}

For their first assignment, students had to write a review of no more than 1,000 words of a single Web 2.0-style application that would assist their team task; they were provided with a list of applications; some students were permitted to review applications of their own choice. The reviews were written and presented to all other students via a private wiki. The students were provided with clear directions as to the process from the start to the finish, including an estimation of the time they were to spend on the task, with explicit instructions on the format and presentation, and the individual steps to be taken to complete it. The assignment achieved several purposes. First, it introduced students new to wikis to this kind of application (most were, however, familiar with wikis). At the same time, however, it also actively demonstrated to students that wikis are not just about 'co-authoring' of content in the manner often presumed to be the best or only use of a wiki. This task was deliberately individual: yet students could either before, during or after their own writing, also read the

3 Note that while we do not discuss the traditional essay (Assignment 3), we would emphasise that this more traditional assessment task materially contributed to the success of the others by both reassuring individuals that they would, in some measure, be assessed as individuals (obviating a normal complaint by students about groupwork) and also by acting as an end point which - in its simplicity and normality - allowed students to focus attention on the different ways of working needed in the other tasks. 
contributions of others and could also observe the revision process being undertaken by their comrades and then, if they wished, revisit their own work. Effectively, we required the students to engage in individual work in a collective setting - a form of parallel play that students reported was very useful in gaining confidence in their own work as they observed others completing the same task.

Simultaneously, by completing a review of the affordances and usefulness of a particular collaborative application, the students were eased into the context of teamwork and online collaborative needs, including the simple requirement to consult other team members to ensure each team reviewed various applications, rather than all reviewing the same one. This use of the wiki form of social media, therefore, is different in its emphases to many uses that are suggested to academics and teachers. Critically, Assignment One drew on the affordance of social media that is often forgotten: students are readers as well as writers and that reading other student work, in process, is very useful. The wiki afforded us the opportunity to make this happen in a simple, anonymous, largely unconscious and spontaneous fashion - very different to the situation if we had required students to consciously share their work in a classroom.

\section{Assignment Two: a team report on Internet economics}

For the primary assignment, the team presentation, students had to work together to prepare publicly available report that addressed the question: "what is the fundamental economic basis of Internet commerce?” While the particular website at which this publication was to appear was stipulated (www.openzine.com), and we provided very clear criteria for the assessment of the final output, both the specific content of the report, the way to address or understand the question, and the methods by which the team would work together were left for the teams themselves to discuss, determine, and then implement. The Openzine site offered tools and templates for users to create their own magazines in a more professional and structured manner than a simple 'website', allowing the display of videos and other rich media as well as more traditional text. It had built-in collaborative tools and users were not required to have even basic coding skills (although many of our students are do). This site was chosen primarily to orient students towards the idea of writing for a general public, rather than writing for the eyes only of their teachers; it also enabled all teams - as part of a formal process - to peer assess each other's work.

While we provided explicit guidance for students about the teamwork processes (as suggested by McLoughlin \& Luca, 2002), we did not specifically indicate how that should occur in practice. Similarly, while there were many classes and resources which provided material to allow students to answer the question, we did not respond to students' requests to explain what the question meant, or how they should answer it and simply referred them to the criteria by which their work was to be assessed. Finally, by utilizing a peer assessment process, teams were able to receive valuable feedback on the direction of their projects prior to the final completion of the task. Students reported that they were motivated by this approach, especially by the public nature of the final result, and that the team experience was, on the whole, a successful one.

We utilised social media in this assignment in two quite different ways. First, we required students to publish online and emphasised to them the use of a website that afforded opportunities for multi-authored work, implicitly enabling them to collaborate via that site. Second, we made clear that teams should choose to use social media technologies of their own choice to promote collaborative discussion, decision making and project management: 
while we did not specify a particular application, the reviews conducted in the first assignment prompted them to consider the merits of various applications such as Openzine, Google.knol, Notaland, Solodox, Sharenow, Ning and Diigo.

Furthermore, since some groups involved off-campus students, and all had students who were busily juggling competing demands for their time both at university and in other parts of their lives, the very fact that we insisted on a team approach created a need for students to think seriously about how online collaborative software might aid them. While in Assignment One, we had specified exactly how and what to do with the wiki, so that students might then discover, as if by accident, the unanticipated value of parallel play, in Assignment Two, we made no specific requirements about social software use for collaboration so that students, following from Assignment One, could seek out and then, together, decide upon the technologies that would best suit their team.

\section{Social media in action: outcomes and conclusions}

No educational design ever plays out according to plan: indeed it would be worrying if it did, for such a result would suggest that students were simply fitting in to an experience preordained for them rather than engaging, participating and shaping the experience to suit their needs and expectations. We discovered that many aspects of NET205 worked effectively, either as planned or in some unexpected way: for example, the lack of precision in our instructions on the team report actually reduced the number of questions from students about length, content, and so on that are normally experienced by staff in these kinds of units. Yet we also observed and are now addressing weaknesses or other matters which need refinement in preparation for future offerings of the unit. For example, the authenticity of the deadline of the team task - a simple deadline for completion - was reported by students to have impeded their ability to plan and manage competing priorities: rather than schedule and manage the project by setting their own internal deadlines, teams tended to leave the task to the last couple of weeks, despite guidance against that approach. This finding reinforces our view that the effective use of social media depends as much on the design of the assessments, taking into account the difference between reality and authenticity, as on the use of technology itself.

Importantly, however, we have gained two valuable insights into the realities of social media use in higher education that not only inform our redesign, but also serve to highlight general conditions which can serve as the foundation for other educators' engagement with the complexity of grappling with the interaction of students, learning experienced and the relevance and value of social media applications and affordances.

The first insight relates to the nature of team work and social media. The structure of assessment, the requirement to work in teams and the provision of positive support for the use of collaborative tools created an environment which in theory should have led to close cooperation and engagement between team members. Most groups, however, reported that they tended to approach the teamwork task by dividing up the work into relatively equal components and then completing them as individuals, with relatively limited collective input and finalization of the project. This collective individualism may well be a strategically successful response to the requirements of contemporary university study (which is, in almost all cases now, combined with work as well as many other commitments outside of education). Yet it also reflects the way that social media, at least as a current cultural practice, leads to 'networked individualism' (Wellman et al., 2003), in which Internet technologies both increase the amount of connectivity between people, yet reduce the intensity of the 
cooperation and collaboration thereby achieved. In other words, perhaps social media makes it easier to be part of a joint endeavour without actually having to engage in close, shared work. Technologies for group collaboration do not, of themselves, solve many of the key issues of group collaboration which are largely concerned with subtle negotiation within a group of identities, roles, and expectations of performance. Social media might well complicate these negotiations by hiding them behind the icons, links and other visible screensigns of 'sharing' and 'collaboration'. The success of the 'collaboration' in the wiki in Assignment One (when no sharing was explicitly discussed, but individuals worked together without realising it) contrasts with some of the problems for groups when they actually attempted to 'work together'. This conclusion squares with Eijkman's caution that while social software might drive an epistemological shift to participatory knowledge construction, this shift is not reducible to the technology (2009).

Our second broad insight into social media usage within higher education is that educators might expect or require students to use particular technologies, but that students will work with the tools that are at hand, or which make sense to them for collaboration. For some groups the technology of the face-to-face meeting worked well; some others exploited the very 1980s technologies of chat and email. While a few made use of the tools we had hinted at, others rapidly reprised the wiki from Assignment One and used it for their main assignment, while others utilised the open collaboration service at vyew.com; some used a blog to keep track of their group's progress and in preparation for their report on the group process. Similarly, the requirement for public presentation worked to motivate students, but students also quickly chose different, more easily used modes of expression than the one we had attempted to mandate. The students found that the OpenZine layouts were too restrictive and, thus, most of the groups used it only to redirect readers to another site, usually a wiki, at which they had actually done their publication.

Ultimately, success with social media in higher education probably depends on exploring and validating students' choices of the tools to hand, with which they are comfortable and familiar and that make sense for the task. Educators might be best to avoid specifying technologies: and instead specify processes and let students discover how the two might interact. It is the "views and perceptions of the users (learners)" (Lee \& McLoughlin, 2008, p. 3) that ultimately determine the affordances of a particular application. And, in establishing and exploiting the use of social media in higher education, we conclude that the design of the social interactions through those tools is more important than the technologies themselves.

\section{References}

Allen, M. (2001). From classes to communities: Internet-based learning and relations of individual learners to one another. In D.Milutinovic and M.Patricelli (Eds), Proceedings of SSGRR-2001 Conference on Advanced Internet for Business and Education (paper no.100). L’Aquila: Scuola Superiore G. Reiss Romoli.

Allen, M. (2009a). Authentic assessment and the Internet: Contributions within knowledge networks. In J.Dron, T.Bastiaens, and C.Xin (Eds), Proceedings of World Conference on E-Learning in Corporate, Government, Healthcare, and Higher Education 2009 (pp.1501-1510). Chesapeake, VA: Association for the Advancement of Computing in Education. Retrieved from http://netcrit.net/content/aaceauthenticassessment2009.pdf

Allen, M. (2009b). Tim O’Reilly and Web 2.0: The economics of memetic liberty and control. Communication, Politics \& Culture, 42(2), 6-23. 
Allen, M., \& Long, J. (2009). Learning as knowledge networking: Conceptual foundations for revised uses of the Internet in higher education. In S.I.Ao, C.Douglas, W.S.Grundfest and J.Burgstone (Eds), Proceedings of the World Congress on Engineering and Computer Science 2009 (pp.652-657). Hong Kong: Newswood. Retrieved from http://www.iaeng.org/publication/WCECS2009/WCECS2009_pp652_ 657.pdf

Anderson, P. (2007). What is Web 2.0? Ideas, technologies and implications for education. Technology and Standards Watch. Bristol: Joint Information Systems Committee (JISC). Retrieved from http://www.jisc.ac.uk/whatwedo/services/techwatch/reports/horizonscanning/hs0701.a spx

Barnett, R. (2004). Learning for an unknown future. Higher Education Research \& Development, 23(3), 247. doi:10.1080/0729436042000235382

Bednarz, N., Garrison, J. W., \& Larochelle, M. (Eds). (1998). Constructivism and Education. Cambridge: Cambridge University Press.

Biggs, J. (2003). Teaching for quality learning at university. Buckingham: Open University Press.

Blais, D. M. (1988). Constructivism: A theoretical revolution in teaching. Journal of Developmental Education, 11(3), 2-7.

Bruns, A. (2007, March). Beyond Difference: reconfiguring education for the user-led age. Presented at ICE3 Conference. Loch Lomond, Scotland. Retrieved from http://snurb.info/node/721

Bruns, A. (2009). Blogs, Wikipedia, Second Life, and beyond: From production to produsage. New York: Peter Lang.

Collis, B., \& Moonen, J. (2008). Web 2.0 tools and processes in higher education: quality perspectives. Educational Media International, 45, 93-106. doi:10.1080/09523980802107179

Crook, C. (2008). Web 2.0 technologies for learning: the current landscape - opportunities, challenges and tensions. London: Becta. Retrieved from http://partners.becta.org.uk/uploaddir/downloads/page_documents/research/web2_technologies_learning.pdf

Diaz, V. (2010). Web 2.0 and emerging technologies in online learning. New Directions for Community Colleges 150, 57-66. Retrieved from http://onlinelibrary.wiley.com/doi/10.1002/cc.405/pdf

Dron, J. (2007). Designing the undesignable: social software and control. Educational Technology and Society, 10(3), 60-71. Retrieved from http://www.ifets.info/journals/10_3/5.pdf

Ebner, M, Holzinger, A, \& Maurer, H. (2007). Web 2.0 Technology: future interfaces for technology enhanced learning. In C.Stephanidis (Ed.), Universal Access in HCI Part III (pp.559-568). Berlin: Springer. Retrieved from http://www.springerlink.com/content/hrp354g32831g2qx/

Eijkman, H. (2009). Dancing with postmodernity: Web 2.0 as a new epistemic learning space. In M. Lee \& C. McLoughlin (Eds.), Web 2.0 based e-learning: Applying Social Informatics for Tertiary Teaching (n.p.). Hershey, PA: IGI. Retrieved from http://ftp.adfa.edu.au/hass/staff/eijkman.html

Fagersjord, A. After convergence: YouTube and remix culture. In J.Hunsinger, L.Klastrup and M.Allen (Eds), International Handbook of Internet Research (pp. 187-200). Boston: Springer.

Gibbs, G. (2006). How assessment frames student learning. In C.Bryan and K.Clegg (Eds), Innovative Assessment in Higher Education (pp.23-36). Oxford: Routledge. 
Gibbs, G., Simpson, C., \& Macdonald, R. (2003, August). Improving student learning through changing assessment-a conceptual and practical framework. Paper presented at the $10^{\text {th }}$ EARLI Conference, Padova. Retrieved from http://www.open.ac.uk/fast/pdfs/Earli-2003.pdf

Gray, K., Thompson, C., Sheard, J., Clerehan, R., \& Hamilton, M. (2010). Students as Web 2.0 authors: Implications for assessment design and conduct. Australasian Journal of Educational Technology, 26(1), 105-122. Retrieved from http://www.ascilite.org.au/ajet/ajet26/gray.pdf

Greenhow, C., Robelia, B., \& Hughes, J. E. (2009). Learning, teaching, and scholarship in a digital age: Web 2.0 and classroom research: What path should we take now? Educational Researcher, 38, 246-259. doi:10.3102/0013189X09336671

Gulikers, J.T.M, Bastiaens, T.J., and Kirschner, P.A. (2004). A five-dimensional framework for authentic assessment. Educational Technology Research and Development, 52(3), 67-86. Retrieved from http://www.springerlink.com/content/6303651331237707/fulltext.pdf

Harasim, L., Hiltz, S.R., Teles, L. and Turoff, M. (1995). Learning networks: a field guide to teaching and learning online. Cambridge, MA: MIT Press.

Herrington, J., Reeves, T.C., \& Oliver, R. (2006). A model of authentic activities for online learning. In C. Juwah (Ed.), Interactions in online education: implications for theory and practice (pp. 91-103). Oxford: Routledge.

Hiltz, S.R. (1998). Collaborative learning in asynchronous learning networks: Building communities. Invited Address presented at WEB98 conference, Rolando,FL. Retrieved from: http://web.njit.edu/ hiltz/collaborative_learning_in_asynch.htm.

Jenkins, H. (2009). Confronting the challenges of participatory culture. Cambridge, MA: MIT Press.

Joughin, G. (2009). Assessment, Learning and Judgement in Higher Education: A Critical Review. In Assessment, Learning and Judgement in Higher Education (pp. 1-15). Retrieved from http://dx.doi.org/10.1007/978-1-4020-8905-3_2

Kirkwood, A. (2008). Assessment and student learning: a fundamental relationship and the role of information and communication technologies. Open Learning, 23(1), 5. doi $10.1080 / 02680510701815160$

Lee, M. J., \& McLoughlin, C. (2008). Harnessing the affordances of Web 2.0 and social software tools: Can we finally make "student-centered" learning a reality? In Proceedings of World Conference on Educational Multimedia, Hypermedia and Telecommunications (pp. 3825-3834). Cheasapeake, VA: AACE. Retrieved from http://www.editlib.org/p/28915

Luca, J., \& McMahon, M. (2006). Developing multidisciplinary teams through selfassessment, supported with online tools. In Proceedings of World Conference on Educational Multimedia, Hypermedia and Telecommunications (pp. 1855-1860).

Manovich, L. (2009). The Practice of Everyday (Media) Life: From Mass Consumption to Mass Cultural Production? Critical Inquiry, 35(2), 319-331. Retrieved from http://www.journals.uchicago.edu/doi/pdf/10.1086/596645

McLoughlin, C. and Lee, M. (2007). Social software and participatory learning: Pedagogical choices with technology affordances in the Web 2.0 era. Proceedings of the 2007 ASCILITE Conference: ICT: Providing choices for learners and learning, pp. 664675. Retrieved from http://www.ascilite.org.au/conferences/singapore07/procs/mcloughlin.pdf

McLoughlin, C., \& Luca, J. (2002). A learner-centred approach to developing team skills through web 2.0-based learning and assessment. British Journal of Educational 
Technology, 33(5), 571-582. Retrieved from

http://www.ingentaconnect.com/content/bpl/bjet/2002/00000033/00000005/art00292

Morgan, A., \& Beaty, L. (1997). The world of the learner. In F.Marton, D.Hounsell, \&

N.Entwistle (Eds), The Experience of Learning: Implications for Teaching and

Studying in Higher Education (pp. 217-237). Edinburgh: University of Edinburgh.

Retrieved from http://www.tla.ed.ac.uk/resources/ExperienceOfLearning/EoL14.pdf

Musser, J. (2006). Web 2.0 - Principles and practices [Executive summary]. O'Reilly Media.

Retrieved from

http://www.oreilly.com/catalog/web2report/chapter/web20_report_excerpt.pdf

Norman, D. A. (1988). The psychology of everyday things. New York: Basic Books.

O'Reilly, T. (2005, September 9). What Is Web 2.0: Design Patterns and Business Models for the Next Generation of Software. O'Reilly Media. Retrieved from http://oreilly.com/web2/archive/what-is-web-20.html

Payne, C. R. (Ed.) (2009). In Information Technology and Constructivism in Higher

Education. Hershey, PA: IGI. Retrieved from http://www.igi-

global.com/bookstore/TitleDetails.aspx?TitleId=579\&DetailsType=Chapters

Poster, M. (1990). The Mode of Information: Poststructuralism and Social Context (1st ed.). Chicagop, IL: University Of Chicago Press.

Turoff, M. (1991). Computer-Mediated Communication Requirements for Group Support. Journal of Organizational Computing, 1, 85-113. Retrieved from http://web.njit.edu/ turoff/Papers/CMCGS.pdf

Volet, S. \& Järvelä ,S. (2001). Motivation in Learning Contexts: Theoretical Advances and Methodological Implications. Kidlington: Pergamon.

Von Glasersfeld, E. (1995). A constructivist approach to teaching. In L. P. Steffe \& J. Gale (Eds), Constructivism in Education (pp. 3-15). Hillsdale, N.J.: Laurence Erlbaum.

Wellman, B., Quan-Haase, A., Boase, J., Chen, W., Hampton, K., de Diaz, I. I., \& Miyata, K. (2003). The Social Affordances of the Internet for Networked Individualism. Journal of Computer-Mediated Communication, 8(3). Retrieved from http://jcmc.indiana.edu/vol8/issue3/wellman.html

Williams, R., \& Edge, D. (1996). The social shaping of technology. Research policy, 25(6), 865-899.

Wolfe, C. (Ed.) (2001). Learning and Teaching on the World Wide Web. San Diego, CA: Academic Press. 